\title{
Inhibition of phosphatidylinositol 3-kinase modifies boar sperm motion parameters
}

\author{
I M Aparicio , M C Gil, M Garcia-Herreros, F J Peña and L J Garcia-Marin \\ Departamento de Medicina y Sanidad Animal, Área de Reproducción and ${ }^{1}$ Departamento de Fisiología, \\ Universidad de Extremadura, Cáceres, Spain \\ Correspondence should be addressed to L J Garcia-Marin, Departamento de Fisiología, Facultad de Veterinaria, \\ Universidad de Extremadura, Avda. de la Universidad, s/n, 10071 Cáceres 10071, Spain; Email: Ijgarcia@unex.es
}

\begin{abstract}
Motility is the most widely used indicator of sperm quality. Besides modulation by the cAMP pathway little is known regarding the intracellular pathways that regulate boar sperm motility. Recently the role of phosphatidylinositol 3-kinase (PI3-K) in the regulation of human sperm motility has been described. Therefore, the aim of this study was to investigate the role of PI3-K in boar sperm kinematics by using the specific PI3-K inhibitor, LY294002. Boar sperm was incubated up to $1 \mathrm{~h}$ in non-capacitating medium in the presence or absence of the cAMP analog, 8Br-cAMP or the PI3-K inhibitor, LY294002 or both. Boar sperm incubated in capacitating medium was treated in the presence or absence of LY294002. First, we have clearly identified that PI3-K is present in whole lysates of boar spermatozoa. Inhibition of PI3-K significantly increased boar sperm straight-line velocity, circular velocity and average velocity without an effect on the percentage of progressively motile spermatozoa in both media. Inhibition of PI3-K induced the same effects on boar sperm velocities as activation of the cAMP/protein kinase A (PKA) pathway and treatment with the PI3-K inhibitor, LY294002 had neither summatory nor synergic effects on boar sperm motion parameters when treated simultaneously with the cAMP analog 8Br-cAMP. Our data suggest that PI3-K plays a negative role, regulating boar sperm motion parameters through a possible inhibition of the cAMP/PKA activating pathway, and since some Computer Aided Sperm Analysis (CASA)-derived parameters have been related to field fertility our results point to the possibility of modulating sperm motile quality by modifying the PI3-K cellular pathway.

Reproduction (2005) 129 283-289
\end{abstract}

\section{Introduction}

Motility is an important function of the mature male gamete and is widely used as an indicator of semen quality, and therefore a knowledge of signal transduction pathways regulating sperm motility is important to gain insight into new methods to increase the fertilizing ability of semen samples, especially those subjected to biotechnological techniques such as cryopreservation. It has been known for a long time that a bicarbonate-sensitive adenylyl cyclase system regulates sperm motility in mammalian spermatozoa (Okamura et al. 1985). Furthermore, recent studies have revealed that incubation under in vitro capacitation conditions in a medium with bicarbonate and calcium induces alterations in boar spermatozoa, including a rise in the intracellular concentration of cAMP (Harrison \& Miller 2000, Harrison 2003) and changes in motility (Holt \& Harrison 2002). Moreover, a recent study has shown that agents that increase intracellular levels of cAMP (e.g. cAMP cell-permeable analogs highly resistant to hydrolysis by phosphodiesterases) stimulate boar sperm motility (Holt \& Harrison 2002). In summary, these studies have shown that sperm motility is critically controlled through modulation of protein kinase A (PKA) activity, achieved by alterations in the intracellular concentration of the messenger molecule, cAMP brought about by changes in adenylyl cyclase activity in boar spermatozoa (Holt \& Harrison 2002).

In addition, there is increasing evidence suggesting a role for different kinases and phosphatases regulating sperm motility (Tash \& Bracho 1994, Vijayaraghavan et al. 2000, Luconi et al. 2001, 2004, NagDas et al. 2002). Recently, the presence of the phosphatidylinositol 3-kinase (PI3-K) has been demonstrated in mouse, hamster and human spermatozoa (Feng et al. 1998, NagDas et al. 2002, Luconi et al. 2004). This family of dimeric enzymes, consisting of a catalytic (p110) and a regulatory subunit (p85), catalyzes the transfer of the $\gamma$-phosphate group of ATP to the D3 position of phosphoinositides (Wymann \& Pirola 1998, Anderson \& Jackson 2003). Moreover, 
besides the production of D3 phosphorylated lipids, PI3-K has an intrinsic protein serine-threonine kinase activity (Wymann \& Pirola 1998, Anderson \& Jackson 2003). Pl3$\mathrm{K}$ is widely expressed in somatic cells and plays an important role in mitogenic signaling and cell survival, cytoskeletal remodeling, metabolic control and vesicular trafficking (Wymann \& Pirola 1998, Anderson \& Jackson 2003). In human spermatozoa, inhibition of PI3-K with two structurally unrelated inhibitors, LY294002 and wortmannin, suggests a negative role for $\mathrm{PI} 3-\mathrm{K}$ in the regulation of the motility process (Luconi et al. 2001, 2004, NagDas et al. 2002, du Plessis et al. 2004). Moreover, inhibition of PI3-K results in an increase in intracellular cAMP levels and in tyrosine phosphorylation of the PKAanchoring protein, AKAP3 in human sperm, which finally results in stimulation of the PKA binding to AKAP3 in sperm tails through the regulatory subunit RII $\beta$ (Luconi et al. 2004). The requirement of PKA binding to AKAP3 for sperm motility was confirmed by the reduction of motility induced by an inhibitor of RII $\beta$-AKAP3 binding (Luconi et al. 2004).

These results strongly suggest that the $\mathrm{PI} 3-\mathrm{K}$ pathway converges negatively on the CAMP/PKA pathway for the regulation of human sperm motility. To date there are no studies in the literature regarding the role of the PI3-K intracellular pathway and its possible interaction with the cAMP/PKA pathway in the regulation of boar sperm motility. Therefore, the aim of this study was to determine whether $\mathrm{PI} 3-\mathrm{K}$ is present in boar sperm and to study its role and relationship with the CAMP/PKA pathway in the regulation of boar sperm motility.

\section{Materials and Methods}

\section{Materials}

Triton X-100 and deoxycholic acid were from Sigma; LY294002 from Calbiochem, La Jolla, CA, USA; anti-rat PI3-K antibody (rabbit whole antiserum) from Upstate Biotechnology, Inc., Lake Placid, NY, USA; Tris/glycine/SDS buffer (10 times concentrated) and Tris/glycine buffer (10 times concentrated) from BIO-RAD; Hyperfilm ECL from Amersham; enhanced chemiluminescence detection reagents and anti-mouse IgG-horseradish peroxidase conjugate from Pierce, Rockford, IL, USA; and nitrocellulose membranes from Schleicher \& Schuell, Keene, NH, USA.

\section{Media}

Sperm capacitating medium, Tyrode's complete medium (TCM) (Green \& Watson 2001) consisted of $96 \mathrm{mM} \mathrm{NaCl}$, $4.7 \mathrm{mM} \mathrm{KCl}, 0.4 \mathrm{mM} \mathrm{MgSO}, 0.3 \mathrm{mM} \mathrm{NaH}_{2} \mathrm{PO}_{4}, 5.5 \mathrm{mM}$ glucose, $1 \mathrm{mM}$ sodium pyruvate, $21.6 \mathrm{mM}$ sodium lactate, $0.5 \mathrm{mM} \mathrm{CaCl}_{2}, 10 \mathrm{mM} \mathrm{NaHCO} 3,20 \mathrm{mM}$ Hepes (pH 7.45) and $3 \mathrm{mg} / \mathrm{ml} \mathrm{BSA}$. TCM was equilibrated with $5 \% \mathrm{CO}_{2}$. A variant of the TCM medium were made by omitting $\mathrm{CaCl}_{2}$ and $\mathrm{NaHCO}_{3}$ and was termed Tyrode's basal medium
(TBM). All Tyrode's media were prepared on the day of use and maintained at an osmolality of 290$310 \mathrm{mOsm} / \mathrm{kg}$ at $\mathrm{pH} 7.45$ at $39^{\circ} \mathrm{C}$.

\section{Collection and washing of semen}

Commercial artificial insemination (Al) doses, from Duroc boars of proven fertility and routinely used for $\mathrm{Al}$, diluted to $30 \times 10^{6}$ sperm cells $/ \mathrm{ml}$, in $80 \mathrm{ml}$ of a commercial extender (MR-A; Kubus, Madrid, Spain), and stored for $12 \mathrm{~h}$ at $17^{\circ} \mathrm{C}$ were obtained from Semen Porcino, Andalucia, SL (Spain). In order to minimize individual boar variation, samples were pooled, using semen from up five boars. Semen was centrifuged once (3 min, $1200 \mathrm{~g}$ ) and washed twice with TBM. Samples of $1.5 \mathrm{ml}$ containing $1 \times 10^{8}$ spermatozoa/ml were pre-incubated for $30 \mathrm{~min}$ at $39^{\circ} \mathrm{C}$ in TBM with LY294002 $(100 \mu \mathrm{M})$ or $0.1 \%$ DMSO. After this pre-incubation time, samples were centrifuged at $1200 \mathrm{~g}$ for $3 \mathrm{~min}$ and extended in $1.5 \mathrm{ml} \mathrm{TBM}+0.1 \%$ DMSO or TBM + LY294002 $(100 \mu \mathrm{M})$ or TBM + 8BrCAMP $(1 \mathrm{mM})$ or TBM + LY294002 $(100 \mu \mathrm{M})+8 \mathrm{Br}$-CAMP $(1 \mathrm{mM})$ or $\mathrm{TCM}+0.1 \%$ DMSO or TCM $+\mathrm{LY} 294002$ $(100 \mu \mathrm{M})$ and incubated for 1 extra hour at $39^{\circ} \mathrm{C}$. The experiments were repeated seven times on seven different days. Preliminary dose-response experiments were performed to select the concentration of DMSO that did not significantly compromise sperm viability.

\section{Identification of PI3-K}

Samples $(1 \mathrm{ml})$ were washed with PBS and sonicated for $5 \mathrm{~s}$ at $4^{\circ} \mathrm{C}$ in lysis buffer: $50 \mathrm{mM}$ Tris/ $\mathrm{HCl}, \mathrm{pH} 7.5,150 \mathrm{mM}$ $\mathrm{NaCl}, 1 \%$ Triton X-100, $1 \%$ deoxycholate, $1 \mathrm{mM}$ EGTA, $0.4 \mathrm{mM}$ EDTA, $2.5 \mu \mathrm{g} / \mathrm{ml}$ aprotinin, $2.5 \mu \mathrm{g} / \mathrm{ml}$ leupeptin, $1 \mathrm{mM}$ phenylmethylsulfonyl fluoride and $0.2 \mathrm{mM} \mathrm{Na}_{3} \mathrm{VO}_{4}$. The homogenate was centrifuged at $10000 \mathrm{~g}\left(15 \mathrm{~min}, 4^{\circ} \mathrm{C}\right)$ and supernatants containing soluble proteins in non-ionic (Triton X-100) and ionic detergents (deoxycholate) were used to analyze protein content in boar spermatozoa.

Proteins in precleared whole cell lysates were resolved in duplicate by SDS-PAGE and transferred to nitrocellulose membranes. Western blotting was performed as previously described (Aparicio et al. 2003) using 1:750 anti-rat-PI3-K whole antiserum as primary antibody. The density of bands was measured using a scanning densitometer (Molecular Dynamics, Sunnyvale, CA, USA) as previously described (Ferris et al. 1999, Tapia et al. 1999).

\section{Motility analysis}

Analysis was based on the examination of 25 consecutive digitalized images obtained from a single field using a $\times 20$ negative-phase contrast objective. Images were taken with a time lapse of $1 \mathrm{~s}$ - the image capture speed was therefore one every $40 \mathrm{~ms}$. The number of objects incorrectly identified as spermatozoa was minimized on the monitor by using the playback function. With respect to the setting parameters for the CASA program, an object 
Table 1 Definition of motility descriptors.

\begin{tabular}{|c|c|c|}
\hline Name & Units & Description \\
\hline Curvilinear velocity (VCL) & $\mu \mathrm{m} / \mathrm{s}$ & $\begin{array}{l}\text { Measures the sequential } \\
\text { progression along the } \\
\text { true trajectory }\end{array}$ \\
\hline Linear velocity (VSL) & $\mu \mathrm{m} / \mathrm{s}$ & $\begin{array}{l}\text { Measures the straight } \\
\text { trajectory of the spermatozoa } \\
\text { per unit of time }\end{array}$ \\
\hline Mean velocity (VAP) & $\mu \mathrm{m} / \mathrm{s}$ & $\begin{array}{l}\text { Measures the mean trajectory } \\
\text { of the spermatozoa per unit } \\
\text { of time }\end{array}$ \\
\hline $\begin{array}{l}\text { Linearity } \\
\text { coefficient (LIN) }\end{array}$ & $\%$ & VSL/VCL $\times 100$ \\
\hline $\begin{array}{l}\text { Straightness } \\
\text { coefficient (STR) }\end{array}$ & $\%$ & VSL/VAP $\times 100$ \\
\hline $\begin{array}{l}\text { Wobble } \\
\text { coefficient (WOB) }\end{array}$ & $\%$ & VAP/VCL $\times 100$ \\
\hline $\begin{array}{l}\text { Mean lateral head } \\
\text { displacement (ALH) }\end{array}$ & $\mu \mathrm{m}$ & $\begin{array}{l}\text { Measures the mean head } \\
\text { displacement along the } \\
\text { curvilinear trajectory }\end{array}$ \\
\hline $\begin{array}{l}\text { Frequency of head } \\
\text { displacement (BCF) }\end{array}$ & $\mathrm{Hz}$ & $\begin{array}{l}\text { Measures the number of } \\
\text { lateral oscillations of the } \\
\text { sperm head around the } \\
\text { mean trajectory }\end{array}$ \\
\hline
\end{tabular}

with an average path velocity (VAP) $<10 \mu \mathrm{m} / \mathrm{s}$ was considered immobile, while objects with a velocity $>15 \mu \mathrm{m} / \mathrm{s}$ were considered motile. Objects with velocities between 16 and $35 \mu \mathrm{m} / \mathrm{s}$ were considered as medium speed objects; those with a velocity $>35 \mu \mathrm{m} / \mathrm{s}$ were considered rapid objects. Spermatozoa deviating $<10 \%$ from a straight line were designated linear motile. Table 1 shows the sperm motility descriptors (based on those described by Mortimer (2000)) obtained by CASA analysis.

\section{Statistical analysis}

The means and S.E.M. were calculated for descriptive statistics. Data were first tested using a Kolmogorov-Smirnov test to determine the normality of the data distribution. In view of the Gaussian distribution of the data gathered, a multivariate ANOVA was used followed by the Scheffé test to determine the effect of the PI3-K inhibitor and the cAMP analog or both on boar sperm kinematics. All analysis were performed using SPSS version 11.1 for Windows software (SPSS, Inc., Chicago, IL, USA). The level of significance was set at $P \leq 0.05$.

\section{Results}

\section{Identification of PI3-K in boar spermatozoa}

We first established that PI3-K was present in boar spermatozoa. Class I PI3-Ks are heterodimers of approximately $200 \mathrm{kDa}$, composed of a 110-120 kDa catalytic subunit tightly and constitutively associated with a 50-100 kDa regulatory subunit, of which p85 is the prototype (Wymann \& Pirola 1998). We performed a Western blot using an antiserum against the regulatory subunit of class I PI3-K (Fig. 1). The anti-PI3-K regulatory subunit antibody

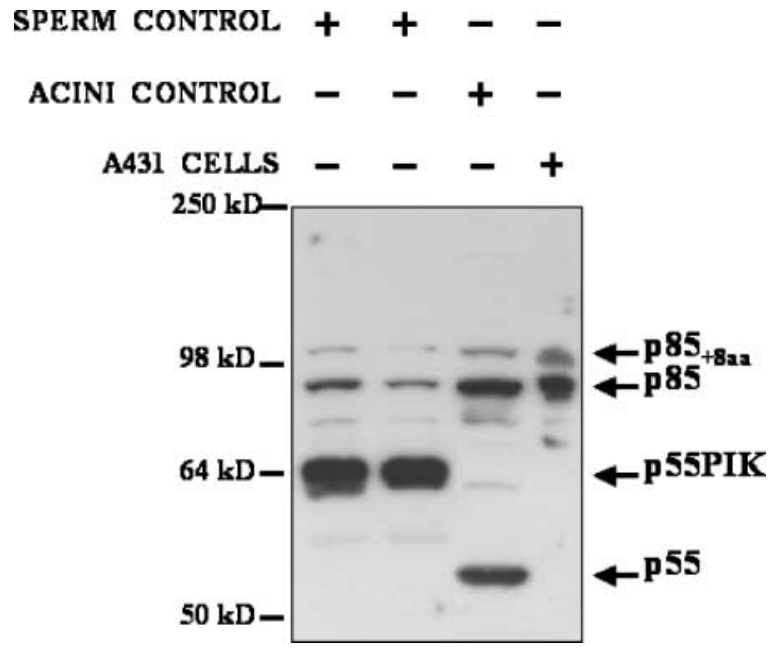

Figure 1 Immunoblot analysis of whole cellular lysates with anti-PI3$\mathrm{K}$ antibody; $15 \mu \mathrm{g}$ of proteins from precleared whole cell lysates were loaded in each lane, resolved in duplicate by SDS-PAGE and transferred to nitrocellulose membranes. Western blotting was performed as described in Materials and Methods. Lanes 1 and 2, boar spermatozoa $\left(1 \mathrm{ml}, 1 \times 10^{8}\right.$ cells) were washed and sonicated in lysis buffer and supernatant containing soluble proteins in non-ionic (Triton X$100)$ and ionic detergents (deoxycholate) were used to analyze protein content. Lanes 3 and 4 , as control we used whole cell lysates from rat pancreatic acini and A431 cells in which the presence of the regulatory subunit of $\mathrm{PI}-\mathrm{K}$ has been previously identified.

recognized three protein bands of approximately 100, 85 and $65 \mathrm{kDa}$ in whole cell lysates of boar spermatozoa (Fig. 1, lanes 1 and 2). These results can be explained by the fact that three genes have been identified for class IA PI3-K regulatory subunits, namely those coding for $\mathrm{p} 85 \alpha$, p85 $\beta$ and a p55PIK (Wymann \& Pirola 1998, Anderson \& Jackson 2003). Moreover, the p85 $\alpha$ mRNA can be alternatively spliced giving rise to a 53-55 kDa protein termed p55 or p55/AS53 (Wymann \& Pirola 1998, Anderson \& Jackson 2003). Both p85 and p55 may carry a 24-nucleotide insertion, which results in an eight-amino acid insert (Wymann \& Pirola 1998, Anderson \& Jackson 2003). These can be confirmed from the data obtained with whole control cell lysates from pancreatic acini and A431 cells showing different isoforms of the PI3-K regulatory subunit: p85+8aa, p85 and p55 (Fig. 1, lanes 3 and 4 respectively). The $65 \mathrm{kDa}$ protein band recognized in boar spermatozoa lysates could be identified as the p55PIK regulatory subunit, which is expressed mainly in male reproductive tissues (Pons et al. 1995, Wymann \& Pirola 1998, Anderson \& Jackson 2003).

\section{Involvement of different intracellular pathways in boar spermatozoa kinematics}

Current knowledge indicates that sperm motility is critically controlled through modulation of PKA activity (Holt \& Harrison 2002). This modulation is achieved by alterations in the intracellular concentration of CAMP, and two important effectors of motility in the sperm's environment, 
bicarbonate and calcium, have been identified as direct activators of adenylyl cyclase (Okamura et al. 1985, Gross et al. 1987, Holt \& Harrison 2002). Moreover, in boar spermatozoa a recent study has shown that bicarbonate or cBIMPS, a cAMP analog, stimulates motility by inducing a faster, more linear type of progression (Holt \& Harrison 2002).

Our results show that treatment of boar spermatozoa with the cAMP analog, $8 \mathrm{Br}-\mathrm{cAMP}(1 \mathrm{mM}, 1 \mathrm{~h})$, or incubation in a capacitation medium (TCM, $1 \mathrm{~h}$ ), with bicarbonate and calcium, or treatment with the specific PI3-kinase inhibitor, LY294002 $(100 \mu \mathrm{M}, 1 \mathrm{~h})$ did not modify the percentage of motile or progressive motile spermatozoa compared with sperm incubated in TBM alone (Fig. 2).

To determine whether the effect of the cAMP analog could be associated with changes in boar sperm kinematics we have determined these parameters by CASA after $1 \mathrm{~h}$ treatment with $8 \mathrm{Br}$-cAMP $(1 \mathrm{mM})$. As shown in Table 2 a significant effect of 8Br-cAMP was observed on curvilinear velocity $(\mathrm{VCL})$, linear velocity (VSL), mean velocity or VAP, wobble coefficient (WOB), lateral head displacement (ALH) and frequency of head displacement (or beat cross-frequency, BCF), whereas no significant effects were detected on linearity coefficient (LIN) and straightness coefficient (STR). Similar results were obtained when boar spermatozoa were incubated in TCM (Table 3), which is in agreement with the fact that incubation under in vitro capacitation conditions increases intracellular cAMP levels in boar sperm (Gadella \& Harrison 2000, 2002).

We next investigated the effect of the specific Pl3-kinase inhibitor, LY294002 on boar spermatozoa kinematics. The treatment of boar spermatozoa with LY294002 (100 $\mu$ M, $1 \mathrm{~h}$ ) caused a clear and significant increase in VCL, VSL, VAP, LIN and WOB, whereas no significant effects were detected on STR, ALH or BCF. The modification of sperm motion parameters observed after LY294002 treatment was similar to the results observed in samples treated with 8Br-cAMP (Table 2) or incubated in TCM (Table 3).

Finally, we wanted to know the combined effect of these treatments on boar sperm motion parameters. Inhibition of $\mathrm{PI} 3-\mathrm{K}$ in spermatozoa treated with $8 \mathrm{Br}$-cAMP induced a modification in sperm kinematics similar to the results obtained in sperm treated only with the analog of cAMP without any synergic effect (Table 2). Moreover, incubation of boar spermatozoa with the PI3-K inhibitor, LY294002 in a capacitation medium induced a significant increase in VCL, VSL, VAP, WOB, ALH and BCF (Table 3), which was similar to the

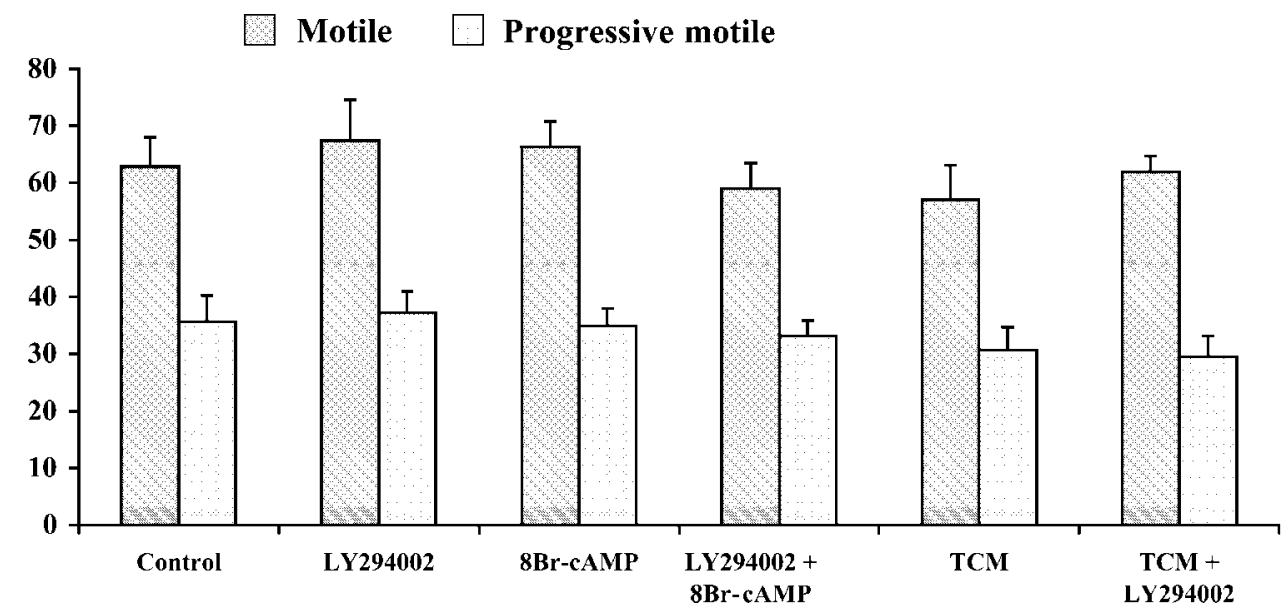

Figure 2 Effect of LY294002 on motile and progressive motile boar spermatozoa. Sperm was incubated in a non-capacitating medium (Control) or in a capacitating medium (TCM) for $1 \mathrm{~h}$ at $39^{\circ} \mathrm{C}$ in the absence or presence of 8Br-cAMP (1 mM) or LY294002 (100 $\mu$ M) or both. Values (\%) are means \pm S.E.M. of seven independent experiments in duplicate.

Table 2 Effect of the cAMP analog 8Br-cAMP or the PI3-K inhibitor LY294002 on boar sperm motion parameters incubated $1 \mathrm{~h}$ in TBM. Sperm was washed, incubated in a non-capacitating medium (TBM) for $1 \mathrm{~h}$ at $39^{\circ} \mathrm{C}$ in the absence or presence of $8 \mathrm{Br}-\mathrm{CAMP}(1 \mathrm{mM})$ or LY294002 $(100 \mu \mathrm{M})$ or both. Values are means \pm S.E.M. of seven independent experiments in duplicate.

\begin{tabular}{|c|c|c|c|c|}
\hline & Control & LY294002 $(100 \mu \mathrm{M})$ & 8Br-cAMP (1 mM) & LY294002 + 8Br-cAMP \\
\hline $\operatorname{VCL}(\mu \mathrm{m} / \mathrm{s})$ & $50.4 \pm 2.3^{\mathrm{a}}$ & $76.85 \pm 5.6^{b}$ & $90.9 \pm 3.2^{\mathrm{b}}$ & $79.9 \pm 6.1^{b}$ \\
\hline $\operatorname{VSL}(\mu \mathrm{m} / \mathrm{s})$ & $26.4 \pm 1.9^{a}$ & $47.85 \pm 2.3^{b}$ & $56.2 \pm 3.8^{\mathrm{b}}$ & $53.2 \pm 3.9^{\mathrm{b}}$ \\
\hline $\operatorname{VAP}(\mu \mathrm{m} / \mathrm{s})$ & $32.7 \pm 1.8^{\mathrm{a}}$ & $57.8 \pm 3.4^{\mathrm{b}}$ & $68.8 \pm 3.6^{\mathrm{b}}$ & $63.1 \pm 4.5^{\mathrm{b}}$ \\
\hline LIN (\%) & $52.2 \pm 2.5^{\mathrm{a}}$ & $63.1 \pm 2.7^{b}$ & $61.5 \pm 2.5$ & $66.8 \pm 1.7^{\mathrm{b}}$ \\
\hline WOB (\%) & $64.8 \pm 1.7^{\mathrm{a}}$ & $75.6 \pm 1.6^{\mathrm{b}}$ & $75.5 \pm 1.7^{\mathrm{b}}$ & $79.1 \pm 1.2^{\mathrm{b}}$ \\
\hline $\mathrm{ALH}(\mu \mathrm{m})$ & $2.0 \pm 0.05^{\mathrm{a}}$ & $2.7 \pm 0.2$ & $3.1 \pm 0.1^{b}$ & $2.7 \pm 0.2$ \\
\hline $\mathrm{BCF}(\mathrm{Hz})$ & $9.1 \pm 0.2^{\mathrm{a}}$ & $9.0 \pm 0.3$ & $7.8 \pm 0.3^{b}$ & $7.2 \pm 0.4^{\mathrm{b}}$ \\
\hline
\end{tabular}

Within a row, values with different superscripts are statistically different from each other, so that for $(a-b), P<0.05$. 
Table 3 Effect of the PI3-K inhibitor LY294002 on boar sperm motion parameters incubated $1 \mathrm{~h}$ in TCM. Sperm was washed, incubated in a non-capacitating medium (TBM) or in a capacitating medium (TCM) for $1 \mathrm{~h}$ at $39^{\circ} \mathrm{C}$ in the absence or presence of LY294002 $(100 \mu \mathrm{M})$. Values are means \pm S.E.M. of seven independent experiments in duplicate.

\begin{tabular}{lccc}
\hline & Control & TCM & $\begin{array}{c}\text { TCM + LY294002 } \\
(100 \mu M)\end{array}$ \\
\hline VCL $(\mu \mathrm{m} / \mathrm{s})$ & $50.4 \pm 2.3^{\mathrm{a}}$ & $67.75 \pm 2.55$ & $87.35 \pm 5.0^{\mathrm{b}}$ \\
VSL $(\mu \mathrm{m} / \mathrm{s})$ & $26.4 \pm 1.9^{\mathrm{a}}$ & $40.95 \pm 5.3$ & $52.75 \pm 5.0^{\mathrm{b}}$ \\
VAP $(\mu \mathrm{m} / \mathrm{s})$ & $32.75 \pm 1.85^{\mathrm{a}}$ & $49.65 \pm 6.15$ & $66.65 \pm 4.9^{\mathrm{b}}$ \\
WOB $(\%)$ & $64.85 \pm 1.75^{\mathrm{a}}$ & $72.45 \pm 2.65$ & $75.95 \pm 1.6^{\mathrm{b}}$ \\
ALH $(\mu \mathrm{m})$ & $2.0 \pm 0.05^{\mathrm{a}}$ & $2.55 \pm 0.15^{\mathrm{b}}$ & $3.15 \pm 0.11^{\mathrm{b}}$ \\
BCF $(\mathrm{Hz})$ & $9.1 \pm 0.17^{\mathrm{a}}$ & $8.4 \pm 0.4$ & $7.7 \pm 0.2^{\mathrm{b}}$ \\
\hline
\end{tabular}

Within a row, values with different superscripts are statistically different from each other, so that for $(a-b), P<0.05$.

increase obtained after incubation with 8Br-cAMP in TBM (compare Tables 2 and 3).

\section{Discussion}

In the present study we show that $\mathrm{PI}$-K protein is present in boar spermatozoa and that the inhibition of $\mathrm{PI}-\mathrm{K}$ activity by LY294002 induces a significant modification of different boar sperm motion parameters without any effect on total or progressively motile spermatozoa. We additionally show that both inhibition of the PI3-K pathway and activation of the CAMP pathway have similar effects on boar sperm motion parameters without any synergic effects, suggesting a close cross-talk between both signaling pathways.

The presence of PI3-K regulatory subunit has been reported in human and hamster spermatozoa as an unique band of $85 \mathrm{kDa}$ and identified as the p85 regulatory subunit of class IA PI3-K (NagDas et al. 2002, Luconi et al. 2004, Nauc et al. 2004). However, immunoblotting experiments strongly suggest the presence of at least two isoforms of the $\mathrm{PI} 3-\mathrm{K}$ regulatory subunit in boar spermatozoa (Fig. 1). The high molecular weight protein bands present in whole boar sperm lysates could be identified as the p85 PI3-K regulatory subunit, with or without the eight-amino acid insert (Wymann \& Pirola 1998, Anderson \& Jackson 2003), as compared with the p85 $\mathrm{PI} 3-\mathrm{K}$ regulatory subunit present in control cells, pancreatic acini and A431 cells (Fig. 1). However, the low molecular weight protein band present in whole boar sperm lysates has not correspondence with the $\mathrm{p} 55 \mathrm{PI} 3-\mathrm{K}$ regulatory subunit present in rat pancreatic acini (Fig. 1). A possible explanation could be the presence in boar spermatozoa of the new PI3-K regulatory subunit, p55PIK that is abundant in adult testis tissue (Pons et al. 1995, Wymann \& Pirola 1998). In summary, our results show for the first time the presence of the p85 PI3-K regulatory subunit in boar spermatozoa in addition to a second regulatory subunit of approximately $60 \mathrm{kDa}$ probably related to the p55PIK regulatory subunit. However, further experiments will be necessary to identify exactly this regulatory subunit of $\mathrm{PI} 3-\mathrm{K}$ present in boar spermatozoa.
Most of the studies in boar semen have used CASA systems just to make an objective measurement of motility (Abaigar et al. 1999, Eriksson et al. 2001, Peña et al. 2003a). Although the technology to objectively measure this intrinsic ability of sperm cells has improved in recent years, the practical meaning of the changes in the motion parameters of the spermatozoa observed in our experiment is difficult to interpret, since few experiments have been addressed at determining the real meaning of the changes of sperm kinematics. Nevertheless, accuracy and precision of CASA systems has allowed detection of subtle changes in sperm motion and the subsequent improvement of discrimination among treatments in laboratory studies of new seminal extenders, cryopotectants, or other steps of aliquots processing (e.g. centrifugation) of a given sperm suspension (Amann \& Katz 2004). A more objective determination of motility is important since this parameter can be considered like a functional test, as the exact motion parameter that is shown by a cell is a direct determination of the energy status of this sperm (Quintero-Moreno et al. 2004). As a result, the CASA-subjected study of motility can be included in the group of functional tests that can be considered as useful for in vivo predictive evaluation of an ejaculate (Quintero-Moreno et al. 2004). In this sense, our mean values obtained in boar sperm motion parameters incubated in control conditions, noncapacitation medium (TBM) for $1 \mathrm{~h}$ at $39^{\circ} \mathrm{C}$ (Table 2), are within the range obtained by others authors (Holt et al. 1996, Abaigar et al. 1999, Quintero-Moreno et al. 2004), which supports the use of this experimental approach to study the possible involvement of the PI3-K intracellular pathway in the regulation of motility of boar spermatozoa.

Recent results show an important role for PI3-K in human and hamster sperm motility (Luconi et al. 2001, 2004, NagDas et al. 2002, du Plessis et al. 2004). However, the effect of the inhibition of PI3-K is different depending on the species under study; inhibition of this kinase triggers an increase in human sperm motility, including hyperactivation (Luconi et al. 2001, 2004, du Plessis et al. 2004), whereas its inhibition decreases the hyperactivation during capacitation of hamster sperm motility (NagDas et al. 2002).

Our results show no effect of $\mathrm{PI} 3-\mathrm{K}$ inhibition in the percentage of progressively motile spermatozoa, and this differs from human studies in which the inhibition of PI3-K leads to an increase in the percentage of progressively motile spermatozoa (Luconi et al. 2001, 2004, du Plessis et al. 2004). This fact may be due, at least partially, to a more abaxial insertion of the boar sperm flagellum leading the spermatozoa of this species to a less linear pattern of motility (Briz et al. 1995). However, a significant increase of sperm velocities, VCL, VAP and VSL was observed in boar spermatozoa treated with the PI3-K inhibitor, LY294002, which is in agreement with the results obtained in human sperm using the same inhibitor (Luconi et al. 2001). Significant increases were observed also in other motility descriptors such as LIN and WOB when 
incubated in the basal media (TBM) in the presence of LY294002. Our results show that the PI3-K pathway negatively regulates boar sperm motion parameters and at the same time confirm previous studies in human semen (Luconi et al. 2001, 2004, du Plessis et al. 2004). It is interesting to note that $\mathrm{PI}-\mathrm{K}$ inhibition presents similar effects to the freezing-thawing process in the kinematics of boar sperm (Peña et al. 2003b).

Current knowledge of boar spermatozoa indicates that motility is controlled by activating adenylyl cyclase to produce increased levels of cAMP, which activate PKA (Holt \& Harrison 2002). Moreover, one important effector of motility in the sperm's natural environment, bicarbonate, has been identified as direct activator of a bicarbonatesensitive adenylyl cyclase (Wuttke et al. 2001). A recent study in human sperm has shown that inhibition of PI3-K results in an increase of intracellular cAMP levels (Luconi et al. 2004) and these authors therefore propose that PI3-K negatively regulates human sperm motility by interfering with the CAMP/PKA intracellular pathway (Luconi et al. 2004). Our results using 8Br-cAMP, TCM, LY294002 or these treatments simultaneously, suggest that the involvement of the PI3-K pathway in boar sperm motility is related to a negative effect in the cAMP/PKA pathway. This conclusion is based on the following results: (i) activation of the CAMP/PKA pathway or inhibition of the $\mathrm{PI} 3-\mathrm{K}$ pathway had the same effects on boar sperm motion parameters; (ii) PI3-K activity inhibition had neither summatory nor synergic effects on boar sperm motion parameters when they were treated in the presence of the cAMP analog 8Br-cAMP; and (iii) the effect on motion parameters by natural activation of the cAMP/PKA pathway after incubation in a capacitation medium with bicarbonate was not modified by inhibition of the PI3-K pathway in boar spermatozoa.

In summary, our results allow us to conclude that the $\mathrm{PI} 3-\mathrm{K}$ pathway seems to play a negative role in the regulation of boar sperm motion parameters. This work suggests the plausible modulation of boar sperm motility by specific inhibition of the PI3-K pathway.

\section{Acknowledgements}

We thank Mercedes Gómez for her technical assistance. I M A was supported by a Doctoral Grant from Consejería de Educación, Junta de Extremadura, Spain. This work received financial support from The Ministry of Science and Technology of Spain AGL 2001-0153 (GAN). The authors declare that there is no conflict of interest that may affect the impartiality of this Scientific work.

\section{References}

Abaigar T, Holt WV, Harrison RA \& del Barrio G 1999 Sperm subpopulations in boar (Sus scrofa) and gazelle (Gazella dama mhorr) semen as revealed by pattern analysis of computer-assisted motility assessments. Biology of Reproduction $6032-41$.
Amann RP \& Katz DF 2004 Reflections on CASA after 25 years. Journal of Andrology 25 317-325.

Anderson KE \& Jackson SP 2003 Class I phosphoinositide 3-kinases. International Journal of Biochemistry and Cell Biology 35 $1028-1033$.

Aparicio IM, Garcia-Marin LJ, Andreolotti AG, Bodega G, Jensen RT \& Bragado MJ 2003 Hepatocyte growth factor activates several transduction pathways in rat pancreatic acini. Biochimica et Biophysica Acta 1643 37-46.

Briz MD, Bonet S, Pinart B, Egozcue J \& Camps R 1995 Comparative study of boar sperm coming from the caput, corpus, and cauda regions of the epididymis. Journal of Andrology $\mathbf{1 6}$ $175-188$.

du Plessis SS, Franken DR, Baldi E \& Luconi M 2004 Phosphatidylinositol 3-kinase inhibition enhances human sperm motility and sperm-zona pellucida binding. International Journal of Andrology $2719-26$.

Eriksson BM, Vazquez JM, Martinez EA, Roca J, Lucas X \& Rodriguez-Martinez H 2001 Effects of holding time during cooling and of type of package on plasma membrane integrity, motility and in vitro oocyte penetration ability of frozen-thawed boar spermatozoa. Theriogenology 55 1593-1605.

Feng H, Sandlow JI \& Sandra A 1998 The c-kit receptor and its possible signaling transduction pathway in mouse spermatozoa. Molecular Reproduction and Development 49 317-326.

Ferris HA, Tapia JA, García LJ \& Jensen RT 1999 CCKA receptor activation stimulates p130Cas tyrosine phosphorylation, translocation and association with $\mathrm{Crk}$ in rat pancreatic acinar cells. Biochemistry 38 1497-1508.

Gadella BM \& Harrison RA 2000 The capacitating agent bicarbonate induces protein kinase A-dependent changes in phospholipid transbilayer behavior in the sperm plasma membrane. Development 127 2407-2420.

Gadella BM \& Harrison RA 2002 Capacitation induces cyclic adenosine $3^{\prime}, 5^{\prime}$-monophosphate-dependent, but apoptosis-unrelated, exposure of aminophospholipids at the apical head plasma membrane of boar sperm cells. Biology of Reproduction 67 340-350.

Green CE \& Watson PF 2001 Comparison of the capacitation-like state of cooled boar spermatozoa with true capacitation. Reproduction 122 889-898.

Gross MK, Toscano DG \& Toscano WA Jr 1987 Calmodulinmediated adenylate cyclase from mammalian sperm. Journal of Biological Chemistry $2628672-8676$.

Harrison RA 2003 Cyclic AMP signalling during mammalian sperm capacitation - still largely terra incognita. Reproduction in Domestic Animals 38 102-110.

Harrison RA \& Miller NG 2000 cAMP-dependent protein kinase control of plasma membrane lipid architecture in boar sperm. Molecular Reproduction and Development 55 220-228.

Holt C, Holt WV \& Moore HD 1996 Choice of operating conditions to minimize sperm subpopulation sampling bias in the assessment of boar semen by computer-assisted semen analysis. Journal of Andrology 17 587-596.

Holt WV \& Harrison RA 2002 Bicarbonate stimulation of boar sperm motility via a protein kinase A-dependent pathway: between-cell and between-ejaculate differences are not due to deficiencies in protein kinase A activation. Journal of Andrology 23 557-565.

Luconi M, Marra F, Gandini L, Filimberti E, Lenzi A, Forti G et al. 2001 Phosphatidylinositol 3-kinase inhibition enhances human sperm motility. Human Reproduction 16 1931-1937.

Luconi M, Carloni V, Marra F, Ferruzzi P, Forti G \& Baldi E 2004 Increased phosphorylation of AKAP by inhibition of phosphatidylinositol 3-kinase enhances human sperm motility through tail recruitment of protein kinase A. Journal of Cell Science 117 $1235-1246$.

Mortimer ST 2000 CASA practical aspects. Journal of Andrology 21 515-524. 
NagDas SK, Winfrey VP \& Olson GE 2002 Identification of ras and its downstream signaling elements and their potential role in hamster sperm motility. Biology of Reproduction 67 1058-1066.

Nauc V, de Lamirande E, Leclerc P \& Gagnon C 2004 Inhibitors of phosphoinositide 3-kinase, ly294002 and wortmannin, affect sperm capacitation and associated phosphorylation of proteins differently: $\mathrm{Ca}(2+)$-dependent divergences. Journal of Andrology 25 573-585.

Okamura N, Tajima Y, Soejima A, Masuda H \& Sugita Y 1985 Sodium bicarbonate in seminal plasma stimulates the motility of mammalian spermatozoa through direct activation of adenylate cyclase. Journal of Biological Chemistry 260 9699-9705.

Peña FJ, Johannisson A, Wallgren M \& Rodriguez MH 2003a Antioxidant supplementation in vitro improves boar sperm motility and mitochondrial membrane potential after cryopreservation of different fractions of the ejaculate. Animal Reproduction Science 78 85-98.

Peña FJ, Johannisson A, Wallgren M \& Rodriguez-Martinez H 2003 b Assessment of fresh and frozen-thawed boar semen using an annexin- $V$ assay: a new method of evaluating sperm membrane integrity. Theriogenology 60 677-689.

Pons S, Asano T, Glasheen E, Miralpeix M, Zhang Y, Fisher TL et al. 1995 The structure and function of p55PIK reveal a new regulatory subunit for phosphatidylinositol 3-kinase. Molecular and Cellular Biology 15 4453-4465.
Quintero-Moreno A, Rigau T \& Rodriguez-Gil JE 2004 Regression analyses and motile sperm subpopulation structure study as improving tools in boar semen quality analysis. Theriogenology $\mathbf{6 1}$ 673-690.

Tapia JA, Ferris HA, Jensen RT \& Garcia LJ 1999 Cholecystokinin activates PYK2/CAKbeta by a phospholipase C-dependent mechanism and its association with the mitogen-activated protein kinase signaling pathway in pancreatic acinar cells. Journal of Biological Chemistry $2741261-1271$.

Tash JS \& Bracho GE 1994 Regulation of sperm motility: emerging evidence for a major role for protein phosphatases. Journal of Andrology 15 505-509.

Vijayaraghavan S, Mohan J, Gray H, Khatra B \& Carr DW 2000 A role for phosphorylation of glycogen synthase kinase-3alpha in bovine sperm motility regulation. Biology of Reproduction 62 1647-1654.

Wuttke MS, Buck J \& Levin LR 2001 Bicarbonate-regulated soluble adenylyl cyclase. Journal of the Pancreas 2 154-158.

Wymann MP \& Pirola L 1998 Structure and function of phosphoinositide 3-kinases. Biochimica et Biophysica Acta 1436 127-150.

Received 3 August 2004

First decision 12 October 2004

Accepted 12 November 2004 